Berkala Ilmu Perpustakaan dan Informasi, Vol. 14, No. 2, Desember 2018, Hal. 214-225 DOI: $10.22146 /$ bip.32602

ISSN 1693-7740 (Print), ISSN 2477-0361 (Online)

Tersedia online di https://jurnal.ugm.ac.id/bip

\title{
Analisis kepuasan pemustaka terhadap kualitas layanan perpustakaan di perguruan tinggi vokasi dengan metode Servqual dan Importance-Performace Analysis
}

\author{
Renanda Nia Rachmadita ${ }^{1}$ dan Wibowo Arninputranto ${ }^{2}$ \\ ${ }^{1}$ Prodi Manajemen Bisnis, Jurusan Teknik Bangunan Kapal, PPNS \\ ${ }^{2}$ Prodi Teknik Keselamatan dan Kesehatan Kerja, Jurusan Teknik Permesinan Kapal, PPNS \\ Email : renanda_nia@yahoo.com
}

Naskah diterima: 23 Januari 2018, direvisi: 3 Juni 2018, disetujui: 2 Juli 2018

\begin{abstract}
ABSTRAK
Pendahuluan. Perguruan Tinggi Vokasi wajib memberikan pelayanan terbaik dalam fasilitas, lingkungan belajar, dan civitas akademika yang dapat mendukung proses pembelajaran yang sesuai dengan karakteristik pendidikan vokasi. Perpustakaan sebagai salah satu fasilitas di perguruan tinggi yang berperan menjadi pusat referensi harus memiliki kualitas layanan yang sesuai dengan harapan pemustakanya. Penelitian ini bertujuan untuk mengukur tingkat kepuasan pelayanan yang diberikan oleh perpustakaan di perguruan tinggi bidang vokasi.

Metode Penelitian. Penyebaran kuesioner ditujukan kepada pemustaka sebanyak 150 orang responden yang meliputi mahasiswa dan dosen, di mana kuesioner tersebut disusun berdasarkan lima dimensi Servqual.

Data Analisis. Analisa dilakukan dengan cara menganalisa gap antara persepsi dan harapan serta menggunakan metode Importance-Performance Analysis.

Hasil dan Pembahasan. Analisis gap diketahui bahwa keseluruhan dimensi Servqual tersebut bernilai negatif. Sehingga perlu adanya tindakan perbaikan agar memenuhi harapan pemustaka. Dengan menggunakan Importance-Performance Analysis didapatkan bahwa atribut P10 (Perpustakaan perlu menyediakan katalog online yang memadai) harus diprioritaskan terlebih dahulu, dan diperbaiki dalam peningkatan pelayanan perpustakaan.

Kesimpulan dan Saran. Dengan adanya perbaikan ini diharapkan pemustaka perpustakaan dapat lebih optimal dalam menggunakan layanan di Perpustakaan sesuai dengan kebutuhannya.
\end{abstract}

Kata kunci: Servqual; Harapan dan Persepsi; Tingkat Kepuasan; Perpustakaan

\section{ABSTRACT}

Introduction. Library in Vocational Higher Education is required to provide the best services in facilities, learning environmentbased on the characteristics of vocational education. This study aims to measure the level of satisfaction of library services in vocational colleges.

Data Collection Method. The questionnaires were distributed to 150 respondents including students and lecturersbased on five dimensions of Servqual.

Data Analysis. The analysis was conducted by identifying the gap between perception and expectation using Importance-Performance Analysis method.

Results and Discussions. Overall, the analysis if the gap for all Servqual dimensions was negative. Some services needto be improved to meet user expectations. By using Importance-Performance Analysis, itwas found that the attribute P10 (Library needs to provide an adequate online catalog) should be prioritized. .

Conclusions. It is expected that the library can improve the services based on the users' needs. .

Keywords: Servqual; Hope and Perception; Level of Satisfaction; Library 


\section{A. PENDAhuluan}

Tujuan pembelajaran Perguruan Tinggi Vokasi adalah memberi bekal kemampuan dan keahlian khusus kepada mahasiswa. Tersedianya layanan pada pendidikan vokasi dibutuhkan untuk memberikan pelayanan yang terbaik meliputi fasilitas, lingkungan belajar, dan civitas akademika yang dapat mendukung proses pembelajaran yang sesuai dengan karakteristik pendidikan vokasi (Kusumanigrum, 2016). Kualitas layanan merupakan faktor penting dalam pendidikan vokasi. Perguruan Tinggi Vokasi perlu menjamin bahwa pelayanan yang diberikan, dapat memberi kesan positif pada civitas akademika (Ibrahim, Rahman, \& Yasin, 2012). Perpustakaan adalah salah satu unit dalam perguruan tinggi yang memiliki peran penting, bahkan perpustakaan disebut juga sebagai "Jantung Perguruan Tinggi" (Kim, 2017). Dalam rangka mengembangkan perannya bagi civitas akademika, perpustakaan harus dapat mengakomodasi segala perubahan yang terjadi dan mendukung proses pembelajaran dan intelektual. Dengan adanya perubahan kebutuhan pemustaka dalam proses pencarian informasi dan pembelajaran, maka pihak perpustakaan juga mengubah pelayanan dan fasilitas yang akan diberikan.

Perpustakaan sebagai salah satu fasilitas di Perguruan Tinggi yang berperan menjadi pusat referensi harus memiliki kualitas layanan yang sesuai dengan harapan penggunanya. Sedangkan untuk mengukur kualitas layanan, perpustakaan juga harus dilakukan penilaian melalui akreditasi dan sertifikasi perpustakaan. Proses akreditasi dan sertifikasi perpustakaan digunakan untuk mengupayakan peningkatan kualitas perpustakaan (Komarudin, 2016). Dengan demikian perlu adanya pengukuran kualitas layanan yang diberikan oleh perpustakaan, agar fasilitas dan bahan pustaka yang dimiliki dapat sesuai dengan kebutuhan pemustaka. Penelitian tentang kepuasan pemustaka dapat dilakukan dengan cara mendapatkan respon dari pemustaka dari kuesioner yang dibagikan pada pemustaka, sehingga didapatkan gambaran secara global tentang kepuasan pemustaka (Irianti, 2017).
Penelitian tentang persepsi dan harapan merupakan penelitian yang paling banyak diminati dalam area kualitas pelayanan pada beberapa bidang ilmu. Diantaranya yaitu : Parasuraman, dkk (1988) mengembangkan instrumen yang terdiri dari 22 item pertanyaan Servqual untuk menilai persepsi konsumen terhadap kualitas pelayanan. Yousapronpaiboon (2014) menginves-tigasi kualitas pelayanan pada perguruan tinggi di Thailand dengan menggunakan instrumen pada lima dimensi Servqual (Reliability, Assurance, Tangibles, Empathy, Responsiveness). Analisa tingkat kepuasan pemustaka di Fakultas MIPA Universitas Gadjah Mada Yogyakarta menggunakan analisa berdasarkan karaktristik lima dimensi metode Servqual telah dilakukan dan dapat menunjukkan hasil yang dapat menggambarkan tingkat kepuasan pemustaka (Harmoko, 2013). Chui, Ahmad, Bassim, \& Zaimi (2016) mengevaluasi kualitas pelayanan pada sebuah Perguruan Tinggi Swasta di Malaysia dengan tujuan menentukan apakah variabel kualitas pelayanannya sesuai dengan ketentuan yang ada industri pendidikan. Penelitian tersebut menggunakan analisis gap untuk menentukan apakah terdapat gap pada masing-masing atribut kualitas pelayanan. Akhlaghi, Amini, \& Akhlaghi (2012) menilai kualitas pelayanan pendidikan yang ada di perguruan tinggi vokasi berdasarkan penilaian mahasiswa dengan menggunakan Model Servqual. Dahan, Taib, Zainudin, \& Ismail (2016) meneliti tentang pengukuran persepsi dan kepuasan mahasiswa terhadap pelayanan yang diberikan oleh pihak perpustakaan UMP Malaysia berdasarkan Model Libqual.

Berdasarkan penjelasan tersebut, maka penelitian ini bertujuan untuk mengukur tingkat kepuasan pelayanan yang diberikan oleh pihak perpustakaan di perguruan tinggi bidang vokasi. Instrumen yang digunakan adalah berdasarkan dimensi Servqual yaitu dimensi RATER (Responsiveness, Assurance, Tangible, Emphaty dan Reliability). Servqual yang dikembangkan pertama kali oleh Parasuraman, dkk dikembangkan berdasarkan pada apa yang dialami konsumen terhadap apa yang seharusnya terjadi, hal ini dikenal dengan nama 
gap model (Podbrežnik, 2014). Servqual telah mengalami perkembangan dan merupakan sebuah instrumen pengukuran kualitas pelayanan perpustakaan yang efektif dan telah diterapkan pada berbagai macam kondisi perpustakaan di seluruh penjuru dunia, baik itu pada perpustakaan umum maupun perpustakaan khusus (Ahmed \& Shoeb, 2009). Di samping itu, Servqual juga merupakan instrumen yang sangat mudah digunakan untuk mengidenfikasi kualitas pelayanan dari persepsi pengguna perpustakaan (Sahu, 2007). Instrumen yang dibuat menyesuaikan kondisi perpustakaan, untuk mengukur kualitas pelayanan dan memberikan informasi yang dapat membantu pihak perpustakaan untuk memahami kelebihan dan kekurangannya. Cara untuk meningkatkan kualitas pelayanan perpustakaan pada penelitian akan ditentukan tingkat kepentingannya berdasarkan metode IPA (Importance Performance Analysis). IPA merupakan sebuah teknik sederhana dan efektif yang dapat membantu praktisi dalam mengidentifikasi prioritas perbaikan kualitas beserta strategistrategi yang harus ditempuh (Ban, Ban, \& Tuşe, 2016). Penelitian oleh Ban dkk (2016) mengimplementasikan metode IPA untuk dapat menentukan prioritas secara lebih detail, sehingga analisa yang dihasilkan dapat membantu pihak manajerial untuk mengambil keputusan. Izadi, Jahani, Rafiei, Masoud \& Vali (2017) juga telah mengimplemtasikan metode IPA untuk dapat mengukur kinerja saat dilakukan pengukuran dan menentukan tingkat kepentingan pada setiap item.

\section{B. TINJAUAN PUSTAKA \\ Kualitas Layanan}

Kualitas layanan adalah cara memahami gambaran nyata kinerja layanan yang ada dari sudut pandang pemustaka (Hossain, 2016). Banyak penelitian yang berminat untuk mempelajari kualitas layanan di lingkungan Perpustakaan (Jayasundara, 2011). Parasuraman, dkk (1988) mengembangkan metode kualitas jasa yang disebut Service Quality (Servqual) dengan tujuan untuk meningkatkan layanan kepada pemustaka layanan. Perpustakaan perlu menilai kualitas layanan, karena perpustakaan mempunyai peran krusial dalam kampus (Kim, 2017). Walaupun informasi saat ini bisa didapatkan dimanapun, Perpustakaan masih merupakan tempat yang disukai untuk mendapatkan informasi oleh pengguna (Applegate, 2009). Berbagai studi telah melaporkan peningkatan penggunaan fasilitas perpustakaan (McKay, 2011), sehingga layanan di Perpustakaan sangat penting untuk dinilai untuk dapat dikembangkan.

Untuk mengukur Servqual, maka dibuatlah lima dimensi yang dapat mewakili pengukuran tersebut. Lima dimensi kualitas layanan ini dikembangkan oleh Parasuraman et al. (1988), dalam Syukri (2014) pengukuran kepuasan akan menggunakan dimensi RATER yaitu Responsiveness, Assurance, Tangible, Emphaty dan Reliability. Nilai layanan didapatkan dengan mengukur gap antara harapan dan persepsi yang diterima oleh pengguna layanan.

\section{Importance-Performance Analysis (IPA)}

Metode analisi IPA diperkenalkan pertama kali oleh Martilla dan James (1977) telah banyak diterapkan dalam berbagai bidang ilmu. IPA merupakan alat analisis yang digunakan untuk menganalisis tingkat kepentingan dan kinerja. Ini bertujuan untuk menentukan atribut mana yang memiliki kinerja rendah dan harus ditingkatkan (Suroto, Nindiani \& Purba, 2017). IPA digunakan untuk mengetahui posisi / perbandingan antara atribut-atribut persepsi dengan atribut-atribut harapan, dimana perbandingan atribut-atribut tersebut digambarkan dalam sebuah diagram kartesius untuk menentukan prioritas layanan yang diinginkan oleh pelanggan melalui keempat kuadran dalam diagram kartesius tersebut.

\section{METODE PENELITIAN Tempat Penelitian}

Penelitian dilakukan dengan melakukan survey tingkat kepuasan pemustaka Perpustakaan di salah satu Perguruan Tinggi Negeri bidang Vokasi di Surabaya. Perpustakaan memiliki karakteristik antara lain pelayanan peminjaman buku literatur kepada mahasiswa dan dosen, pelayanan peminjaman buku tugas akhir dan hanya dapat dibaca di 
Perpustakaan, jam operasional Perpustakaan adalah jam 08.00 WIB hingga 16.00 WIB dari hari Senin sampai Jumat, jumlah pustakawan berjumlah dua orang, dengan fasilitas koneksi internet, ruang baca berkapasitas 50 orang dan katalog buku koleksi masih belum online.

\section{Batasan Masalah}

Penelitian ini dilakukan dengan batasan sebagai berikut:

1. Pengambilan sampel pada penelitian ini meliputi meliputi Mahasiswa dan dosen. Mahasiswa yang terpilih sebagai responden yakni mahasiwa yang saat itu sedang mengunjungi perpustakaan. Hal ini dikenal dengan nama teknik pengambilan Accidental Sampling, dikarenakan responden memenuhi kriteria, seperti mudah ditemui, tersedia pada waktu tersebut dan keinginan untuk berpartisipasi dalam memenuhi tujuan penelitian (Etikan, Musa, \& Alkassim, 2016).

2. Penelitian yang dilakukan merupakan penelitian kualitatif, di mana penelitian ini akan menangkap tingkat kepuasan pengguna perpustakaan melalui kuesioner yang diisi oleh responden (pengguna perpustakaan)

3. Penelitian ini meliputi atribut-atribut yang akan digunakan mengacu pada 5 dimensi dalam mengevaluasi kualitas jasa (Servqual) seperti yang disampaikan Parasuraman, Zeithmal dan Berry (1988), yaitu : Bukti langsung (tangibles), Keandalan (reliability), Daya tanggap (responsiveness), Jaminan (assurance), dan Empati.

\section{Penentuan Atribut}

Adapun item-item pertanyaan dalam kuesioner dapat dilihat pada Tabel 1.

\section{HASIL DAN PEMBAHASAN Uji Validitas Dan Uji Reliabilitas}

Untuk melakukan uji validitas dan uji reliabilitas, digunakan software SPSS 20.0. Hasil pengujian validitas kuesioner untuk bagian Persepsi dan Harapan responden pemustaka dapat dilihat pada Tabel 2 .
Berdasarkan nilai $r_{\text {table }}$ pada $\mathrm{n}=150(\mathrm{df}=$ 148) dan $\alpha=0,05$ diperoleh angka 0,16 dan jika dibandingkan dengan nilai $r_{\text {hitung }}$ untuk tiap pertanyaan kuesioner pada bagian persepsi dan pada bagian harapan maka didapat nilai $r_{\text {hitung }}>$ nilai $r_{\text {tabel }}$, sehingga setiap item pertanyaan tersebut valid (Somantri dan Muhidin, 2006).

Dengan menggunakan software SPSS 20.0 maka hasil pengujian reliabilitas kuesioner persepsi dan harapan dapat dilihat pada Tabel 3.

Berdasarkan nilai $\mathrm{r}_{\text {table }}$ pada $\mathrm{n}=150(\mathrm{df}=$ 148) dan $\alpha=0,05$ diperoleh angka 0,16 dan jika dibandingkan dengan Alpha Cronbach's maka diperoleh bahwa nilai Apha Cronbach's > nilai $\mathrm{r}_{\text {tabel}}$, sehingga kuesioner dinyatakan reliabel.

\section{Analisis Tingkat Kepuasan (Analisis Gap)}

Perbedaan antara persepsi dengan harapan membentuk sebuah gap yang digunakan untuk mengukur tingkat kualitas pelayanan. Gap yang bernilai negatif berarti pelayanan yang diterima sangatlah buruk, sehingga tidak ada konsumen yang merasa puas. Sedangkan gap yang bernilai positif menunjukkan bahwa pelayanan yang diberikan sangatlah baik dan konsumen merasa puas (Daniel \& Berinyuy, 2010).

Selengkapnya, dalam Tabel 4 disajikan nilai kesenjangan/gap antara persepsi dengan harapan responden pada tiap item pelayanan Perpustakaan.

Berdasarkan Tabel 4, terlihat bahwa keseluruhan item pertanyaan memiliki nilai gap yang negatif. Hal ini berarti bahwa pelayanan kepada pemustaka Perpustakaan masih berada di bawah harapan responden.

Nilai gap yang paling besar adalah $-1,95$ pada item P10 (Perpustakaan menyediakan katalog online yang memadai), ini dikarenakan pemustaka sudah menganggap bahwa sistem katalog online sangat diperlukan dan pada kenyataannya, sistem katalog yang ada sekarang adalah masih dalam bentuk offline.

Sementara itu, nilai gap paling kecil yakni 0,9 yaitu pada item P8 (Perpustakaan melakukan pengelompokan buku sesuai dengan bidang keilmuan untuk pengguna), ini dikarenakan perpustakaan telah mengelompokan buku sesuai dengan aturan klasifikasi bahan pustaka, namun sedikit belum 
sesuai dengan keinginan pemustaka yang menginginkan pengelompokan buku berdasarkan program studi.

Dari 22 item pertanyaan, diperoleh 3 (tiga) item yang memiliki gap lebih besar dari -1 yaitu P6, P8 dan P15. P6 (Perpustakaan memiliki catatan peminjaman yang akurat) mempunyai nilai gap yang lebih besar dari -1 dikarenakan perpustakaan memang sudah memiliki catatan peminjaman yang akurat, namun pemustaka menginginkan agar catatan tersebut dapat diakses, agar tidak terlambat ketika akan mengembalikan buku yang dipinjam. P8 (Perpustakaan melakukan pengelompokan buku sesuai dengan bidang keilmuan untuk pengguna), mempunyai gap yang lebih tinggi dari -1 karena buku memang sudah dipisah berdasarkan bidang keilmuan. Dan untuk P15 (Perpustakaan memiliki Pustakawan yang terbuka dan sopan terhadap pemustaka), yang juga mempunyai nilai lebih besar dari -1 , disebabkan karena menurut responden, sikap dari pustakawan sudah cukup terbuka dan sopan.

\section{Importance-Performance Analysis}

Dari hasil analisis Gap diketahui bahwa tiap item masih bernilai negatif semua. Dengan demikian, perlu adanya upaya perbaikan. Maka dari itu, untuk meningkatkan kualitas layanan perpustakaan, digunakan ImportancePerformance Analysis (IPA) sebagai alat bantu dalam penelitin ini, agar pihak perpustakaan dapat menentukan tindakan perbaikan sesuai dengan urutan prioritas.

Nilai rata-rata dari ke 22 atribut kualitas jasa Perpustakaan dapat dilihat pada Diagram kartesius pada Gambar 1.

Diagram kartesius pada Gambar 1 menggambarkan pemetaan berdasarkan tingkat persepsi dan tingkat harapan, sehingga pihak manajemen Perpustakaan dapat melakukan evaluasi, perbaikan dan peningkatan kualitas layanan. Adapun interpretasi dari masingmasing kuadran yaitu:

\section{Kuadran I}

Atribut-atribut yang terletak pada kuadran I merupakan atribut yang sangat krusial dan harus segera ditindak lanjuti. Atribut dalam kuadran I tertera pada Tabel 5.

\section{Kuadran II}

Atribut-atribut yang terletak pada kuadran ini dinilai cukup baik dan mampu untuk dipertahankan. Atribut yang masuk dalam kuadran II adalah seperti yang tertera pada Tabel 6.

\section{Kuadran III}

Atribut-atribut yang terletak pada kuadran ini merupakan atribut yang tidak terlalu membutuhkan perhatian khusus. Atribut yang masuk dalam kuadran III adalah seperti yang tertera pada Tabel 7.

\section{Kuadran IV}

Atribut-atribut yang terletak pada kuadran ini dianggap tidak terlalu penting sehingga pihak manajemen perlu mengalokasikan sumber daya yang terkait dengan atribut-atribut tersebut kepada atribut-atribut lain yang mempunyai prioritas penanganan lebih tinggi. Atribut yang masuk dalam kuadran 4 adalah seperti yang tertera pada Tabel 8 .

\section{E. KESIMPULAN}

Berdasarkan analisa, dapat diambil kesimpulan bahwa secara keseluruhan tingkat kepuasan pemustaka sebagai responden, masih jauh dari harapan, ini terlihat dari nilai gap yang bernilai negatif pada semua pertanyaan kuesioner. Nilai gap terbesar adalah $-1,95$ dan terdapat pada item (Perpustakaan menyediakan katalog online yang memadai), dikarenakan sistem katalog yang ada masih dalam bentuk offline dan perlu segera diubah menjadi online.

Perbaikan kualitas layanan perpustakaan dapat dilakukan secara bertahap dengan memperhatikan hasil dari analisa IPA, dimana kuadran I merupakan bagian yang harus segera diperbaiki. Item P1 (Perpustakaan memiliki perlengkapan dan peralatan yang memadai) diperbaiki dengan cara Menambah perlengkapan dan peralatan yang sesuai dengan kebutuhan dan dapat menunjang kinerja perpustakaan. P5 (Perpustakaan memiliki koleksi buku yang sesuai dengan kebutuhan informasi pemustaka) diperbaiki dengan cara mengkoordinasi kebutuhan buku tiap program 
studi yang ada bersama ketua program studi terkait, sehingga buku koleksi dapat sejalan dengan ilmu yang diberikan pada mahasiswa. P10 (Perpustakaan menyediakan katalog online yang memadai) diperbaiki dengan cara merubah sistem manual menjadi sistem online, sehingga pemustaka dapat lebih mudah ketika mencari bahan pustaka. Dan P14 (Perpustakaan memiliki jam operasional yang sesuai dengan keinginan pemustaka) dapat diperbaiki dengan cara menyesuaikan jam buka dengan jam perkuliahan yang berjalan.

\section{DAFTAR PUSTAKA}

Ahmed, S. Z., \& Shoeb, M. H. (2009). Measuring service quality of a public university library in Bangladesh using Servqual. Performance Measurement and Metrics, 10(1), 17-32

Akhlaghi, E., Amini, S., \& Akhlaghi, H. (2012). Evaluating educational service quality in technical and vocational colleges using Servqual model. Procedia - Social and Behavioral Sciences, 46, 5285-5289

Applegate, R. (2009). The library is for studying : Student preferences for study space. Journal of Academic Librarianship, 35, 341-346

Ban, O. I., Ban, A. I., \& Tuşe, D. A. (2016). Importance-Performance Analysis by Fuzzy C-Means algorithm. Expert Systems with Applications, 50, 9-16

Chui, T. B., Ahmad, M. S. bin, Bassim, F. binti A., \& Zaimi, N. binti A. (2016). Evaluation of service quality of private higher education using Service Improvement Matrix. Procedia - Social and Behavioral Sciences, 224, 132-140 Tidak ada issue? Please check again

Dahan, S. M., Taib, M. Y., Zainudin, N. M., \& Ismail, F. (2016). Surveying users' perception of academic library services quality : A case study in Universiti Malaysia Pahang (UMP) library. Journal of Academic Librarianship, 42(1), 38-43
Daniel, C. N., \& Berinyuy, L. P. (2010). Using the Servqual model to assess service quality and customer satisfaction : An empirical study of grocery stores in Umea, Master Thesis. Retrieved from http://umu.divaportal.org/smash/record.jsf?pid=diva2:327 600

Etikan, I., Musa, S. A., \& Alkassim, R. S. (2016). Comparison of convenience sampling and purposive sampling. American Journal of Theoretical and Applied Statistics, 5(1), 1-4

Harmoko, S. (2013). Analisis tingkat kepuasan pemustaka terhadap kualitas layanan pada perpustakaan Fakultas Matematika dan Ilmu Pengetahuan Alam Universitas Gadjah Mada Yogyakarta. Berkala Ilmu Perpustakaan dan Informasi, 9(2), 18-31

Hossain, M. J. (2016) Determining the key dimensions for evaluating service quality and satisfaction in academic libraries, International Information \& Library Review, 48(3), 176-189

Ibrahim, M. Z., Rahman, M. N. A., \& Yasin, R. M. (2012). Assessing students perceptions of service quality in Technical Educational and Vocational Training (TEVT) institution in Malaysia. Procedia - Social and Behavioral Sciences, 56, 272-283

Irianti, P. (2017). Kepuasan pemustaka terhadap fasilitas perpustakaan di Fakultas Psikologi Universitas Gadjah Mada. Berkala Ilmu Perpustakaan dan Informasi, 13(1), 47-55

Izadi, A., Jahani, Y., Rafiei, S., Masoud, A., \& Vali, L. (2017). Evaluating health service quality: using importance performance analysis. International journal of health care quality assurance, 30(7), 656-663

Jayasundara, C. C. (2011). Communication and employee relations in the University Libraries of Sri Lanka : Perception of staff members. Gyankosh-The Journal of Library and Information Management, 2(1), 28-40

Kim, J.-A. (2017). User perception and use of the academic library : A Correlation Analysis. The Journal of Academic Librarianship, 43(3), 209-215 
Komarudin. (2016). Akreditasi perpustakaan perguruan tinggi : Pengalaman perpustakaan STAIN Kediri. Pustakaloka, 8(1), 14-33. https://doi.org/10.21154/ pustakaloka.v8i1.454

Kusumanigrum RR., S. D. (2016). Applying Servqual to improve the quality of service delivery in vocational education in Indonesia. Journal of Management \& Muamalah, 6(2), 77-90

McKay, D. (2011). Spinning straw into gold : A community college library's twenty first century transformation. Community \& Junior College Libraries, 17,1-6

Podbrežnik, I. (2014). Using Servqual for public Library Service Quality Assessment. The British Academy of Management (BAM) Conference, 8, 51-63
Sahu, A. K. (2007). Measuring service quality in an academic library: an Indian case study. Library Review, 56(3), 234-243

Syukri, S. H. A. (2014). Penerapan Customer Satisfaction Index (CSI) dan analisis gap pada kualitas pelayanan Trans Jogja. Jurnal Ilmiah Teknik Industri, 13(2), 103-111

Suroto, Nindiani, A. \& Purba, H. H. (2017). Students' satisfaction on academic services in higher education using ImportancePerformace Analysis. ComTech: Computer, Mathematics and Engineering Applications, 8(1), 37-43

Yousapronpaiboon, K. (2014). Servqual : Measuring higher education service quality in Thailand. Procedia - Social and Behavioral Sciences, 116, 1088-1095 


\section{DAFTAR GAMBAR}

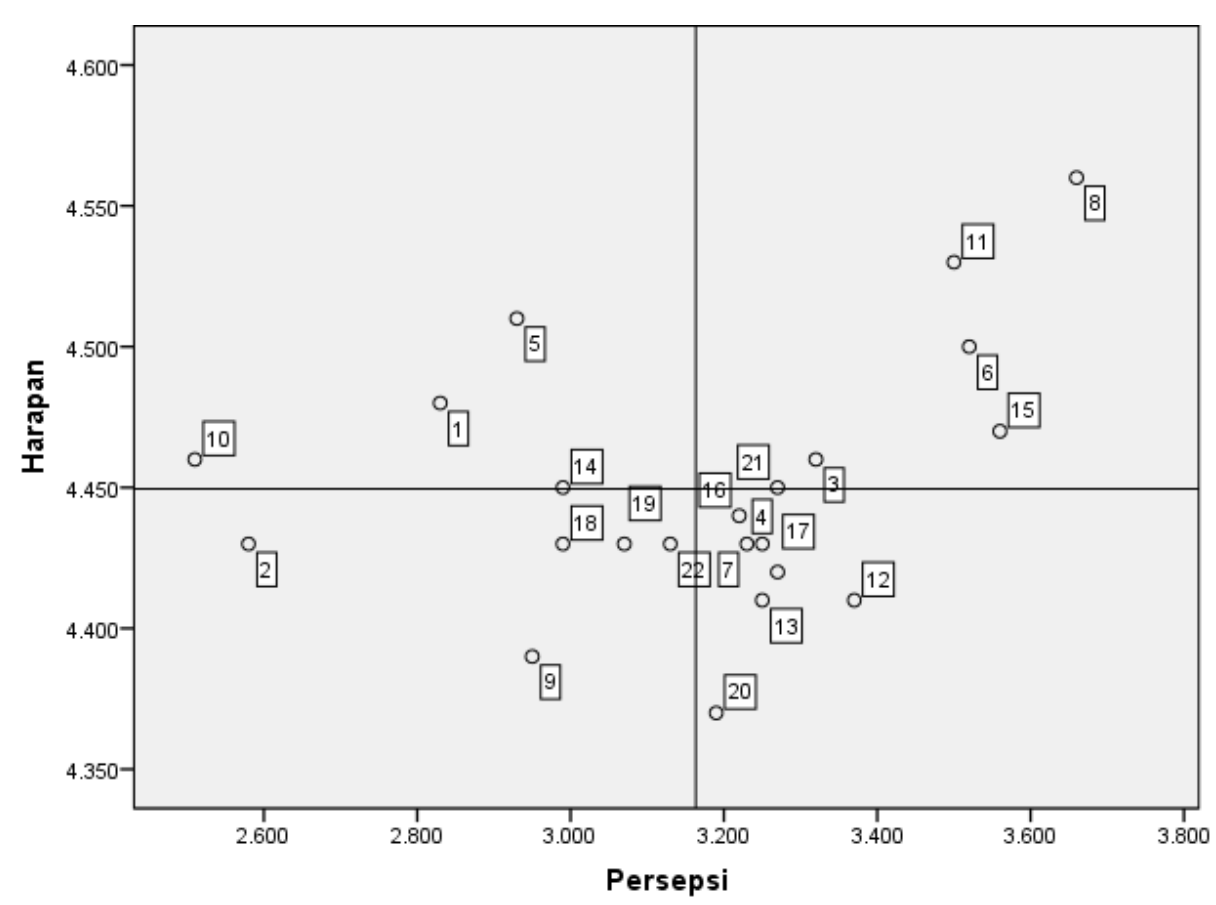

Gambar 1. Diagram Kartesius Importance-Performance Analysis

\section{DAFTAR TABEL}

Tabel 1. Atribut Kuesioner Kepuasan Pemustaka

\begin{tabular}{|c|c|c|}
\hline No & Item Pertanyaan & Dimensi \\
\hline P1 & Perpustakaan memiliki perlengkapan dan peralatan yang memadai. & \multirow{5}{*}{ Tangible } \\
\hline $\mathrm{P} 2$ & Perpustakaan menyediakan peralatan yang up to date. & \\
\hline & Contoh: Komputer dan multimedia, aplikasi pengecekan pinjaman. & \\
\hline P3 & Perpustakaan menyediakan lingkungan Perpustakaan yang kondusif. & \\
\hline P4 & $\begin{array}{l}\text { Perpustakaan memberikan kesan yang baik berkaitan dengan layan an. } \\
\text { Contoh: Memberitahu waktu jatuh tempo dan buku-buku terbaru pada pemustaka. }\end{array}$ & \\
\hline P5 & Perpustakaan memiliki koleksi buku yang sesuai dengan kebutuhan informasi pemustaka. & \multirow{5}{*}{ Reliability } \\
\hline P6 & Perpustakaan memiliki catatan peminjaman yang akurat. & \\
\hline P7 & Perpustakaan memberikan informasi pada pemustaka secara tepat saat layanan diberikan. & \\
\hline P8 & Perpustakaan melakukan pengelompokan buku sesuai bidang keilmuan untuk pemustaka. & \\
\hline P9 & Perpustakaan memiliki papan petunjuk yang bermanfaat bagi pemustaka. & \\
\hline P10 & Perpustakaan menyediakan katalog online yang memadai. & \multirow{4}{*}{ Responsiveness } \\
\hline P11 & Perpustakaan menata koleksi buku di rak sesuai urutan tertentu hingga mudah ditemukan. & \\
\hline P12 & Perpustakaan memberikan layanan yang cepat kepada pemustaka. & \\
\hline $\mathrm{P} 13$ & Perpustakaan memberikan pelayanan pertama secara tepat. & \\
\hline P14 & Perpustakaan memiliki jam operasional yang sesuai dengan keinginan pemustaka. & \multirow{4}{*}{ Assurance } \\
\hline $\mathrm{P} 15$ & Perpustakaan memiliki Pustakawan yang terbuka dan sopan terhadap pemustaka. & \\
\hline P16 & Perpustakaan memiliki Pustakawan yang tidak sibuk send iri saat melayani pemustaka. & \\
\hline P17 & Perpustakaan memiliki Pustakawan berpengetahuan luas untuk menjawab pemustaka. & \\
\hline P18 & Perpustakaan memberikan layanan seperti yang dijanjikan. & \multirow{5}{*}{ Empathy } \\
\hline P19 & Perpustakaan dapat memahami apa saja yang dibutuhkan oleh pemus taka. & \\
\hline $\mathrm{P} 20$ & Perpustakaan memiliki Pustakawan yang selalu ingin membantu pemustaka. & \\
\hline $\mathrm{P} 21$ & $\begin{array}{l}\text { Perpustakaan memiliki Pustakawan yang tulus dalam membantu dan memecahkan } \\
\text { permasalahan yang dialami pemustaka selama berada di Perpustakaan. }\end{array}$ & \\
\hline $\mathrm{P} 22$ & Perpustakaan memiliki Pustakawan yang memberi perhatian khusus kepada pemustaka. & \\
\hline
\end{tabular}


Tabel 2. Hasil Pengujian Validitas Kuesioner

\begin{tabular}{ccccc}
\hline \multirow{2}{*}{ Item } & \multicolumn{2}{c}{ Nilai $\mathbf{r}_{\text {hitung }}$} & Nilai $\mathbf{r}_{\text {tabel }}$ & Kesimpulan \\
\hline P1 & 0,560 & 0,764 & 0,16 & Valid \\
P2 & 0,558 & 0,805 & 0,16 & Valid \\
P3 & 0,564 & 0,815 & 0,16 & Valid \\
P4 & 0,604 & 0,794 & 0,16 & Valid \\
P5 & 0,688 & 0,742 & 0,16 & Valid \\
P6 & 0,710 & 0,785 & 0,16 & Valid \\
P7 & 0,738 & 0,812 & 0,16 & Valid \\
P8 & 0,509 & 0,785 & 0,16 & Valid \\
P9 & 0,698 & 0,824 & 0,16 & Valid \\
P10 & 0,691 & 0,746 & 0,16 & Valid \\
P11 & 0,547 & 0,789 & 0,16 & Valid \\
P12 & 0,679 & 0,834 & 0,16 & Valid \\
P13 & 0,731 & 0,827 & 0,16 & Valid \\
P14 & 0,641 & 0,850 & 0,16 & Valid \\
P15 & 0,646 & 0,818 & 0,16 & Valid \\
P16 & 0,723 & 0,775 & 0,16 & Valid \\
P17 & 0,709 & 0,850 & 0,16 & Valid \\
P18 & 0,741 & 0,830 & 0,16 & Valid \\
P19 & 0,745 & 0,850 & 0,16 & Valid \\
P20 & 0,804 & 0,809 & 0,16 & Valid \\
P21 & 0,785 & 0,803 & 0,16 & Valid \\
P22 & 0,816 & 0,834 & 0,16 & Valid \\
\hline
\end{tabular}

Tabel 3. Hasil Pengujian Reliabilitas Kuesioner

\begin{tabular}{lcc}
\hline Item Penilaian & Persepsi & Harapan \\
\hline $\mathrm{N}$ item & 22 & 22 \\
\hline Nilai Alpha Cronbach's & 0,944 & 0,974 \\
\hline nilai $\mathrm{r}_{\text {table }}$ & 0,16 & 0,16 \\
\hline Kesimpulan & Reliabel & Reliabel \\
\hline Sumber: Data penelitian diolah (2017) & &
\end{tabular}


Tabel 4. Nilai Gap Antara Persepsi dan Harapan Pada Tiap Item Pelayanan Perpustakaan

\begin{tabular}{cccccc}
\hline Dimensi & Item & Persepsi (X) & Harapan (Y) & Gap & Gap Tiap Dimensi \\
\hline \multirow{5}{*}{ Tangible } & P1 & 2,83 & 4,48 & $-1,65$ & \\
& P2 & 2,58 & 4,43 & $-1,85$ & $-1,46$ \\
& P3 & 3,32 & 4,46 & $-1,14$ & \\
& P4 & 3,25 & 4,43 & $-1,19$ & \\
Reliability & P5 & 2,93 & 4,51 & $-1,58$ & \\
& P6 & 3,52 & 4,50 & $-0,98$ & $-1,22$ \\
& P7 & 3,23 & 4,43 & $-1,20$ & \\
& P8 & 3,66 & 4,56 & $-0,90$ & \\
& P9 & 2,95 & 4,39 & $-1,45$ & \\
Responsiveness & P10 & 2,51 & 4,46 & $-1,95$ & \\
& P11 & 3,50 & 4,53 & $-1,03$ & $-1,29$ \\
& P12 & 3,37 & 4,41 & $-1,03$ & \\
& P13 & 3,25 & 4,41 & $-1,16$ & \\
Assurance & P14 & 2,99 & 4,45 & $-1,47$ & \\
& P15 & 3,56 & 4,47 & $-0,91$ & $-1,19$ \\
& P16 & 3,22 & 4,44 & $-1,22$ & \\
& P17 & 3,27 & 4,42 & $-1,15$ & \\
\hline \multirow{5}{*}{ Empathy } & P18 & 2,99 & 4,43 & $-1,45$ & \\
& P19 & 3,07 & 4,43 & $-1,36$ & $-1,29$ \\
& P20 & 3,19 & 4,37 & $-1,17$ & \\
& P21 & 3,27 & 4,45 & $-1,18$ & \\
& P22 & 3,13 & 4,43 & $-1,29$ & \\
\hline
\end{tabular}

Tabel 5. Saran Perbaikan Kualitas Layanan Atribut-Atribut Pada Kuadran I

\begin{tabular}{lc}
\hline \multicolumn{1}{c}{ Pernyataan dan Saran Perbaikan } & Dimensi \\
\hline $\begin{array}{l}\text { Perpustakaan memiliki perlengkapan dan peralatan yang memadai (P1) } \\
\text { Saran Perbaikan : Menambah per lengkapan dan peralatan yang sesuai dengan } \\
\text { kebutuhan dan dapat menunjang kinerja perpustakaan }\end{array}$ & Tangibles \\
\hline $\begin{array}{l}\text { Perpustakaan memiliki koleksi buku yang sesuai dengan kebutuhan informasi } \\
\text { pemustaka (P5) }\end{array}$ & \\
$\begin{array}{l}\text { Saran Perbaikan : Kebutuhan buku koleksi mungkin dapat dik onsultasikan pada } \\
\text { setiap program studi yang ada, sehingga buku koleksi dapat sejalan dengan ilmu }\end{array}$ & Reliability \\
yang diberikan pada mahasiswa. & \\
\hline $\begin{array}{l}\text { Perpustakaan menyediakan katalog online yang memadai (P10) } \\
\text { Saran Perbaikan : Sistem katalog yang ada sekarang hendaknya diubah menjadi }\end{array}$ & Responsiveness \\
sistem online, sehingga pemustaka dapat lebih mudah ketika mencari bahan & \\
pustaka. & \\
\hline $\begin{array}{l}\text { Perpustakaan memiliki jam operasional yang sesuai dengan keinginan pemustaka } \\
\text { (P14) }\end{array}$ & \\
$\begin{array}{l}\text { Saran Perbaikan : Jam buka perpustakaan saat ini ses uai dengan jam kerja } \\
\text { karyawan, dan sebaiknya dapat disesuaikan agar sesuai dengan jam perkuliahan } \\
\text { yang berjalan. }\end{array}$ & Assurance \\
\hline
\end{tabular}


Tabel 6. Saran Perbaikan Kualitas Layanan Atribut-Atribut Pada Kuadran II

\begin{tabular}{lc}
\hline \multicolumn{1}{c}{ Pernyataan dan Saran Perbaikan } & Dimensi \\
\hline $\begin{array}{l}\text { Perpustakaan menyediakan lingkungan Perpustakaan yang kondusif (P3) } \\
\text { Saran Perbaikan : Kapasitas ruang baca dan kenyamanannya dapat } \\
\text { ditingkatkan sesuai dengan kebutuhan pemustaka. }\end{array}$ & Tangibles \\
\hline $\begin{array}{l}\text { Perpustakaan memiliki catatan peminjaman yang akurat (P6) } \\
\text { Saran Perbaikan : Catatan peminj aman sudah tertata, hanya saja layanan dapat } \\
\text { ditingkatkan dengan memberikan kemudahan bagi pemustaka untuk } \\
\text { mengetahui waktu jatuh tempo pengembalian buku. }\end{array}$ & Reliability \\
\hline $\begin{array}{l}\text { Perpustakaan melakukan pengelompokan buku sesuai bidang keilmuan untuk } \\
\text { pemustaka (P8) }\end{array}$ & Reliability \\
$\begin{array}{l}\text { Saran Perbaikan : Perpustakaan memiliki aturan tersendiri untuk } \\
\text { pengelompokan buku. }\end{array}$ & \\
\hline $\begin{array}{l}\text { Perpustakaan menata koleksi buku di rak sesuai urutan tertentu hingga mudah } \\
\text { ditemukan (P11) }\end{array}$ & Responsiveness \\
Saran Perbaikan : Pusatakawan menata buku sesuai kelompok bidang \\
keilmuannya.
\end{tabular}

Tabel 7. Saran Perbaikan Kualitas Layanan Atribut-Atribut Pada Kuadran III

\begin{tabular}{lc}
\hline \multicolumn{1}{c}{ Pernyataan dan Saran Perbaikan } & Dimensi \\
\hline $\begin{array}{l}\text { Perpustakaan menyediakan peralatan yang up to date, Contoh : Kom -puter dan } \\
\text { multimedia, aplikasi pengecekan pinjaman (P2) }\end{array}$ & Tangibles \\
Saran Perbaikan : Sarana dan prasarana dapat ditingkatkan sesuai kebutuhan & \\
\hline $\begin{array}{l}\text { Perpustakaan memiliki papan petunjuk yang bermanfaat bagi pemustaka (P9) } \\
\text { Saran Perbaikan : Memperbanyak papan petunjuk dapat lebih memundahkan } \\
\text { pemustaka dalam mencari bahan pustaka yang sesuai. }\end{array}$ & Reliability \\
\hline $\begin{array}{l}\text { Perpustakaan memberikan layanan seperti yang dijanjikan, Contoh : Memberitahu } \\
\text { pemustaka saat buku yang diinginkan telah tersedia (P18) }\end{array}$ & Empathy \\
$\begin{array}{l}\text { Saran Perbaikan : Perpustakaan dapat menginformasikan tentang buku koleksi } \\
\text { terbaru di papan pengumuman perpustakaan, ini akan memberikan informasi } \\
\text { kepada pemustaka }\end{array}$ & \\
\hline $\begin{array}{l}\text { Perpustakaan dapat memahami apa saja yang dibutuhkan oleh pemus-taka (P19) } \\
\text { Saran Perbaikan : Perpustakaan dapat membuat kotak saran, agar dapat } \\
\text { mengetahui kebutuhan apa saja yang diperukan oleh pemustaka }\end{array}$ & Empathy \\
\hline $\begin{array}{l}\text { Perpustakaan memiliki Pustakawan yang memberikan perhatian khusus kepada } \\
\text { pemustaka (P22) }\end{array}$ & Empathy \\
$\begin{array}{l}\text { Saran Perbaikan : Peningkatan kualitas SDM Pustakawan dapat dilakukan } \\
\text { dengan mengikuti pelatihan peningkatan layanan }\end{array}$ & \\
\hline
\end{tabular}


Tabel 8. Saran Perbaikan Kualitas Layanan Atribut-Atribut Pada Kuadran IV

\begin{tabular}{|c|c|}
\hline Pernyataan dan Saran Perbaikan & Dimensi \\
\hline $\begin{array}{l}\text { Perpustakaan memberikan kesan yang baik berkaitan dengan layanan. (P4) } \\
\text { Saran Perbaikan : Perpustakaan dapat membuat pengumuman di papan } \\
\text { informasi setiap bulan yang berk aitan dengan buku koleksi terbaru ataupun } \\
\text { berkaitan dengan data jatuh tempo buku yang dipinjam oleh pemustaka. }\end{array}$ & Tangibles \\
\hline $\begin{array}{l}\text { Perpustakaan memberikan informasi kepada pemustaka secara tepat saat } \\
\text { layanan diberikan (P7) } \\
\text { Saran Perbaikan : Peningkatan pengetah uan Pustakawan dapat dilakukan } \\
\text { dengan mengikuti pelatihan agar dapat memberi informasi yang tepat pada } \\
\text { pemustaka. }\end{array}$ & Reliability \\
\hline $\begin{array}{l}\text { Perpustakaan memberikan layanan yang cepat kepada pemustaka (P12) } \\
\text { Saran Perbaikan : Peningkatan kualitas layanan oleh Pustak awan dapat } \\
\text { dilakukan dengan mengikuti pelatihan peningkatan layanan. }\end{array}$ & Responsiveness \\
\hline $\begin{array}{l}\text { Perpustakaan memberikan pelayanan pertama secara tepat (P13) } \\
\text { Saran Perbaikan : Peningkatan kualitas layanan oleh Pustakawan dapat } \\
\text { dilakukan dengan mengikuti pelatihan peningkatan layanan. }\end{array}$ & Responsiveness \\
\hline $\begin{array}{l}\text { Perpustakaan memiliki Pustakawan yang tidak sibuk sendiri saat melayani } \\
\text { pemustaka (P16) } \\
\text { Saran Perbaikan : Peningkatan kualitas layanan oleh Pustakawan dapat } \\
\text { dilakukan dengan mengikuti pelatihan peningkatan layanan. }\end{array}$ & Assurance \\
\hline $\begin{array}{l}\text { Perpustakaan memiliki Pustakawan berpengetahuan luas untuk menjawab } \\
\text { pemustaka (P17) } \\
\text { Saran Perbaikan : Peningkatan pengetahuan Pustakawan dapat dilakukan } \\
\text { dengan mengikuti pelatihan yang berkaitan dengan pengetahuan yang } \\
\text { terbaru. }\end{array}$ & Assurance \\
\hline $\begin{array}{l}\text { Perpustakaan memiliki Pustakawan yang selalu ingin membantu pemustaka } \\
\text { (P20) } \\
\text { Saran Perbaikan : Peningkatan kualitas layanan oleh Pustakawan dapat } \\
\text { dilakukan dengan mengikuti pelatihan peningkatan layanan. }\end{array}$ & Empathy \\
\hline $\begin{array}{l}\text { Perpustakaan memiliki Pustakawan yang tulus dalam membantu dan } \\
\text { memecahkan permasalahan yang dialami pemustaka selama berada di } \\
\text { Perpustakaan (P21) } \\
\text { Saran Perbaikan : Peningkatan kualitas layanan oleh Pustakawan dapat } \\
\text { dilakukan dengan mengikuti pelatihan peningkatan layanan. }\end{array}$ & Empathy \\
\hline
\end{tabular}

